\title{
Perspectives on Poverty in Europe. Following in Tony Atkinson's Footsteps
}

\author{
Stephen P. Jenkins ${ }^{1,2,3,4}$
}

Received: 13 February 2019 / Accepted: 19 September 2019 / Published online: 28 September 2019 (c) The Author(s) 2019

\begin{abstract}
I address four topics: how our capacities to monitor poverty in Europe have improved substantially over recent decades; how progress on EU poverty reduction has been disappointing and why this has been; conceptual and measurement issues; and the future direction of EU-level anti-poverty actions. I follow in the footsteps of a giant-my perspectives are essentially elaborations of points made by Tony Atkinson.
\end{abstract}

Keywords Poverty $\cdot$ Material deprivation $\cdot$ Europe $\cdot$ EU-SILC

JEL Classification C81 · D31 · I32

\section{Introduction}

This paper provides a number of perspectives on poverty in Europe, drawing heavily on the work of Tony Atkinson. The paper's title refers to Europe rather than a set of specific countries. The distinction is important: the discourse on poverty within European countries has taken an increasingly Europe-level dimension as the integration process has deepened. This is reflected in the ways in which poverty is now conceptualised, measured, and monitored. The goal of this paper is to illustrate these developments, referring to the historical experience, while also providing empirical evidence about poverty trends using several indicators, together with remarks about the direction of

$凶 \quad$ Stephen P. Jenkins

s.jenkins@1se.ac.uk

1 Department of Social Policy, London School of Economics and Political Science, Houghton Street, London WC2A 2AE, UK

2 Institute for Social and Economic Research, ISER (University of Essex), Wivenhoe Park, Colchester CO3 4SQ, UK

3 Melbourne Institute for Applied Economic and Social Research, MIAESR (University of Melbourne), Parkville VIC 3010, Australia

4 IZA (Institute zur Zukünft der Arbeit), Bonn, Germany 
anti-poverty policy in an era of austerity and greater questioning of the roles of EUlevel versus national institutions and initiatives.

In the course of the paper, I pay homage to Tony Atkinson, a true European and internationalist who was dedicated to reducing poverty everywhere. Tony contributed definitive studies of income distribution, poverty and social inclusion in Europe over several decades, as I shall first briefly explain. For extensive overviews of Tony's work, including many other topics, see inter alia Aaberge et al. (2017) and Jenkins (2017).

Consider, for example, Tony's 1992 study with John Micklewright of the distribution of income in Eastern Europe before the Iron Curtain disappeared. This is distinguished by its originality (few had examined this topic before) and by its careful assemblage of data from a range of sources. Alongside material about earnings inequality are chapters on the distribution of household income, issues of measurement, and discussion of poverty and the safety net. Poverty in Europe (1998), based on Tony's 1990 Yrjö Jahnsson Lectures, is an extensive review of how to measure poverty in Europe and assess differences across years and countries, the economics of poverty, and the political economy of anti-poverty policy in Europe. His 2002 and 2007 books, joint with Bea Cantillon, Eric Marlier, and Brian Nolan, on Social Indicators and The EU and Social Inclusion are landmark studies in the theory and practice of social indicators. This research forms the basis of the extensive set of indicators used by the EU for more than a decade to monitor social inclusion and now institutionalised in their Statistics on Income and Living Conditions (EU-SILC), the source for most of the estimates presented later in this paper. Tony and colleagues' work develops a clear set of principles related to measurement validity and data quality, also acknowledging the practical needs of policy-makers and citizens for transparent and timely information.

The team's work did not stop with their initial analysis (2002) but also considered at length implementation challenges and how to take the EU social inclusion process further forward (the 2007 volume). This continued with the Net-SILC projects that Tony led with Eric Marlier. Their 2010 and 2017 edited volumes (the latter co-edited with Ann-Catherine Guio) are extensive collections considering the strengths and weaknesses of EU-SILC, as well as the potential for modifications and extensions to it. Tony's 2010 Macerata Lecture, although an unpublished working paper, stands out as a valuable review of the progress being made to reduce poverty and increase social inclusion in Europe, written at the time the EU-2020 indicators were being decided upon. Finally, I refer to Tony's 2017 report for the World Bank and his last book (2019). Monitoring Global Poverty brings to a world stage many of the issues Tony had considered in the European context, including going beyond defining poverty only in monetary terms to include additional indicators, the relationships between globally harmonized and national estimates, and careful attention to data requirements and to data quality. Measuring Poverty Around the World continues these themes but does so in broader fashion. Rich countries, including those in Europe, are integrated into the conceptual discussion alongside middle- and low-income countries. The recommendation of Tony's 2017 report to derive genuinely global poverty estimates (rather than the previous practice of having estimates covering middle- and low-income countries only) is taken up again and illustrated in his 2019 book. The World Bank is now implementing the recommendation. 
There are four enduring themes in all of Tony's work that are also reflected in his work on poverty in Europe. First, Tony always believed that the topic of income distribution is an integral part of economics. Thus policy about poverty cannot and should not be seen separately from economic policy. For example, he has written that '[o]ne important argument in favour of a poverty target is that it would place anti-poverty policy on the same footing as macro-economic policy' (1998: 151), and:

We cannot consider anti-poverty policy in isolation from other policies. The scope for financing income maintenance depends on macro-economic policy choices, on levels of government spending, and on rates of inflation. The use of transfer payments or other instruments of anti-poverty policy ... in turn have implications for economic policy. Social and economic policy are interdependent. This may appear obvious, but it remains the case that social policy is often placed in a separate compartment. (Atkinson 1998: 151.)

Second, Tony emphasised the importance of EU-level institutions and actions for making progress against poverty in each Member State. The EU context provided leadership, 'contextualised benchmarking' and mutual learning across countries. Third, Tony believed strongly in the importance of thinking clearly about measurement principles but not in isolation-how these relate to policy formulation and monitoring are key and integral issues as well. And that leads to the fourth theme: that it is essential for poverty analysis and poverty to get the statistical infrastructure right, including data.

Tony also brought two distinctive personal traits to all his work on poverty analysis and poverty. He was an internationalist. Alongside his deep concern and knowledge of the British situation, he was a Europhile, very knowledgeable about Europe and he served various European organisations (for example he was a member of the Conseil d'Analyse Economique advising the French Prime Minister 1997-2001, and of the European Statistical Governance Advisory Board 2009-2011). Global perspectives have always been there too, not only in his final publications. It was in 1998, not 2017 , that Tony wrote: 'as we think about developments in Europe, we should not lose sight of the objective of eliminating world poverty, which in my view has precedence' (1998: 152). Tony's second trait is his progressive and optimistic mind-set when thinking about anti-poverty policy at times when it appears that little progress is being made.

In what follows I elaborate on the Atkinsonian themes that I have drawn attention so far, very much following in the footsteps of a giant. I address four topics. Section 2 shows how our capacities to monitor in Europe have improved substantially over recent decades. Section 3 illustrates how progress on EU poverty reduction has been disappointing and reviews analysis by Tony and others considering the reasons for this. In Sect. 4, I discuss some conceptual and measurement issues with empirical illustrations relating to how we should measure 'poverty' and specify policy targets. In the final section, I consider the future direction of EU-level anti-poverty actions in the light of the earlier discussion, ending by contrasting Tony's optimistic approach with the pessimistic perspectives which are perhaps more prevalent. 


\section{Improvements in Monitoring Capacity and Knowledge}

Designing anti-poverty policies without having an accompanying statistical infrastructure to monitor progress is like building a house on sand rather than rock. Statistical monitoring is an essential part of a poverty and social inclusion policy agenda. As Tony and colleagues have emphasised in the European context, '[w]e need to be particularly concerned about the three-way linkage between policy, vulnerable groups, and indicators' (Marlier et al. 2007: 239). Only then can we determine what the problems are, who is afflicted, and how social policies affect the problems. Frank Vandenbroucke, a Minster in the Belgian Federal Government intimately engaged with the substantial increase in statistical monitoring initiatives under the Belgian presidency of the EU in the 2000s (and a research student of Tony's) stresses a similar point:

'[s]ocial indicators are not ... a miracle cure for the social problems of the EU, but they constitute a key instrument for defining and monitoring policies that are put in place to deal with these problems (Vandenbroucke 2002: $\mathrm{x}-\mathrm{xi}$ ). Vandenbroucke is also clear about the role that Europe can play collectively: "[t]he purpose of the establishment of a common set of indicators is not a naming and shaming exercise. ... The peer review process supports ... mutual learning' (Vandenbroucke 2002: viii).

Table 1 summarises the substantial progress made in the statistical monitoring of poverty and social inclusion in Europe over the last four decades. A reference point for the situation 40 years ago is provided by Malcolm Sawyer's (1976) study of income distribution in OECD countries, with the cross-national comparative statistics based on compilations from national datasets and, controversially in some cases, leading to country 'league table' positions that differed from national perspectives. Over the 1980s, substantial progress was made in the availability of harmonised cross-nationally

Table 1 Milestones in European statistical monitoring of poverty and social exclusion

\begin{tabular}{lll}
\hline Date & Initiatives & EU data \\
\hline $1980 \mathrm{~s}$ & EC Poverty Programmes; major & Compilations of national data sets \\
& Eurostat symposia (1984, 1989) & \\
$1990 \mathrm{~s}$ & First pan-European data: European & ECHP, 1994-2001, 14 MS \\
& Community Household Panel & \\
2000 & Lisbon Council: Open Method of & \\
& Coordination framework with & \\
& National Action Plans & \\
2001 & Atkinson et al. report proposing a & \\
& common EU-wide set of social & \\
& indicators; adopted shortly thereafter & \\
2000 s & EU 'Laeken' indicators (2001), & \\
& subsequently refined & EU-SILC; coverage reflects EU \\
Mid-2000s onwards & Pan-European output-harmonised & enlargement \\
& data: EU-Statistics on Living & \\
2010 & Conditions & \\
& EU2020 targets include a Social & \\
& Inclusion objective &
\end{tabular}


comparable data and hence statistically robust analysis. The Luxembourg Income Study database was in the vanguard and the leading early study based on it is Atkinson et al. (1995).

There were also European initiatives at the same time. During the 1980s, the European Commission funded three Poverty Programmes. Although the programmes were not specifically about statistical infrastructure, there were major symposia in 1984 and 1989 that considered related issues. The 1990s saw the first pan-European data initiative in the field of income distribution, the European Community Household Panel (ECHP), with 14 Member States eventually participating (with data covering 1994-2001). A key feature was the use of input harmonisation-the same survey instrument was fielded in multiple countries.

The next major monitoring milestone was the Lisbon Council of 2000 which established the Open Method of Coordination (OMC) framework. Within the OMC, Member States agree upon common objectives for the EU as a whole, and a set of common indicators to assess national and EU progress towards these goals, accompanied by National Action Plans which encapsulate the country-specific measures for reducing poverty. The issues relating to what those common indicators should be was discussed at length in a report by Tony and colleagues (subsequently published as Atkinson et al. 2002). They proposed a hierarchy of primary indicators of poverty and social inclusion. These leading indicators were to be supported by secondary indicators providing additional detail and covering complementary areas. These were the basis of the 'Laeken' indicators adopted by the EU in 2001 and subsequently refined.

The next major milestone was the introduction of the new pan-European data sets, the EU-SILC, in the mid-2000s. Notably, for the first time, Member States were mandated by law to deliver data to the EU. Compared to the ECHP, these data cover many more countries - reflecting EU enlargement. The social indicators that have to be delivered are specified but countries have some discretion about the instruments they use to collect and produce (though Eurostat provides guidance). In particular, some countries use administrative data registers to collect data, though the majority continue to use household surveys. By contrast with the ECHP, there is output rather than input harmonisation, and so cross-national comparability is harder to achieve.

A dramatic change from the 1990s is that estimates for every EU-SILC indicator are now made available through Eurostat's Online Database (n.d.) and, in addition, the unit record data from which the estimates are derived are much more accessible to academic and other research users than ECHP data ever were. Registered users can gain access much more quickly and easily (the application process is appropriately thorough but much more timely) and the charges are much less prohibitive. (Arguably the difficulties of accessing ECHP unit record data sowed the seeds of the ECHP's demise: see Jenkins 1999.) Access provides opportunities for the scrutiny of official statistics, consideration of alternative definitions, and much other research on related topics including e.g. developments such as the EUROMOD tax-benefit microsimulation model-in which Tony Atkinson played a leading advisory role (Atkinson 2009).

The final monitoring milestone is the agreement of the EU2020 targets in 2010. Alongside four targets referring to employment, R\&D/innovation, climate change and energy, and education, the EU has a fifth target relating to poverty/social exclusion. On the face of it, this is concrete evidence of social policy being considered alongside 
economic policies. I return to consider the monitoring of this target (and Tony's views about it) at the end of this paper.

The substantial improvements in statistical monitoring capacity that have occurred over the last 25 years are illustrated by a comparison with the situation at the end of the 1980s. The European Commission asked Michael O'Higgins and me to undertake a survey of poverty in EU countries (O'Higgins and Jenkins 1990). Our brief was to replicate an earlier Commission study providing poverty estimates for 1975 and to extend it to 1980 and 1985 , all to be done a short deadline. In common with the Sawyer (1976) study, O'Higgins and I had to rely on national data sources and on country correspondents who derived estimates from these following a protocol regarding definitions and coverage that we provided them. We did the best we could but there were issues with incomplete cross-national comparability of the data, and we had coverage of only 12 EU Member States. The data were not always available for precisely the 3 years we sought, and some data were missing altogether. For example for Germany in 1985, we had to derive estimates by projection. There was only one headline indicator - the proportion of persons in income poverty (defined as living in a household with an equivalized income less than half the contemporary mean). Overall, we estimated that the proportion of persons in poverty in the 12 countries considered was around $12.8 \%$ in the mid-1970s (1973/1977), was much the same around 1980 (1978/1981), and rose by just over one percentage point, to $13.9 \%$ in the mid-1980s (1984/1985).

According to Tony Atkinson, 'the European Commission President, Jacques Delors, publicized the estimates ... and their use was instrumental in developing the social dimension of the EU' (2019: 2). However, the results were controversial, so much so that the Commission withdrew our report from circulation without providing an explanation. (It is now available in electronic form from the website of the Publications Office of the European Union.)

The monitoring situation improved over time nonetheless. See, for instance, the comprehensive Eurostat-commissioned research by Hagenaars et al. (1994, 1998) presenting poverty estimates for years around 1988. Notably, the researchers derived their estimates for all 12 EU countries from household budget survey unit record data rather than in a piecemeal fashion as O'Higgins and I had to do. The survey data themselves remained not widely available however. (Distinctively, as well, household resources were measured using consumption expenditure rather than income.)

Nowadays the situation is completely different from the 1980s-estimates are easily accessible and uncontroversial. Information about poverty levels and trends for Member States and the EU as a whole is readily available from Eurostat's Online Database (n.d.). The wealth of information available about poverty and social inclusion is living proof of the impact of Atkinson et al. (2002) pioneering work.

With only nine mouse clicks you can map poverty rates across European countries, with Member States categorised according to values for the headline poverty indicator, the proportion of persons living in a household with an equivalized disposable income less than $60 \%$ of the national contemporary median income. The latest estimates at the time of writing refer to 2016. If you make the clicks, you will see that the highest poverty rates are in Bulgaria, Romania, and Spain, where between one-fifth and one quarter of the population is poor. The lowest poverty rates are in Finland and Denmark, 
with rates of around $10 \%$. Subject to the caveat that definitions differ a little from those used by O'Higgins and Jenkins (1990), current poverty rates are the same order as those we reported. It appears that poverty rates have remained high stubbornly persistent over the last three decades. The next section considers this lack of progress on poverty reduction in more detail drawing on estimates that I downloaded from the Eurostat Online Database (n.d.).

\section{Disappointing Progress in Poverty Reduction}

The EU's headline measure of poverty refers to people living in a household with an equivalized disposable income less than $60 \%$ of the contemporary national median income. This is the 'at risk of poverty' (AROP) rate in Eurostat's terminology. Splicing together series of estimates from the ECHP through to 2004 and from EU-SILC thereafter, and using this headline, one derives a picture of trends from around 1995 through to 2016 for EU15 Member States, as well as shorter series for the 10 new Member States (NMS10) who only joined the enlarged EU in the 2000s. These series are shown in Figs. 1a, 2a. In the other two panels of each figure are series summarizing poverty trends using different definitions from the headline indicator: (b) 'anchored' poverty rates (referring to people living in a household with an equivalized disposable income less than $60 \%$ of the 2005 contemporary national median income), and (c) rates of severe multiple deprivation (the SMD rate is defined later on). Presenting the three series together is intended to facilitate comparisons of similarities in trends over time as the poverty indicator definition is varied. Trends in the AROP rate are the focus of this section; the other two series are discussed in the next section.

Within every panel of Figs. 1 and 2, countries are sorted according to their poverty rate in 2016. The year labels refer to the year that data collection was undertaken. For the two income-based poverty rates, the rates refer to the previous year-when the incomes were earned-with the exception of the UK and Ireland which have currentyear measures. The SMD rate refers to the situation at the date of data collection. The dashed vertical lines mark the beginning of EU-SILC, a reminder of the change in data source and hence potential discontinuity. (There are a few discontinuities in the EU-SILC too, for example, for Spain and France between 2007 and 2008.) The solid vertical line at 2008 marks the onset of the global financial crisis, otherwise known as the Great Recession.

Among EU15 nations, the headline AROP indicator did not fall over the last two decades (Fig. 1a). The trend line for most countries is relatively flat, and the range of the changes over the 20 -year period as a whole is around 5 percentage points. For a majority of countries, the net result is an increase in poverty over the two decades: although flattish, the lines have a slight upward tilt. The disappointing progress is not simply a consequence of the Great Recession: the flattish trend line is the general rule before 2008 in most cases as well as afterwards. And AROP rates do not necessarily rise in the period directly after 2008; indeed there was a small decline in the UK.

However, there are noticeable deviations from the general patterns. For example, AROP rates rose in both Finland and Sweden between the mid-1990s and mid-2000s. AROP rates declined over the mid-2000s in Ireland and also (less noticeably) in Por- 
(a) 'At risk of poverty' (AROP) rates: (percentage with income less than $60 \%$ of contemporary national median income)

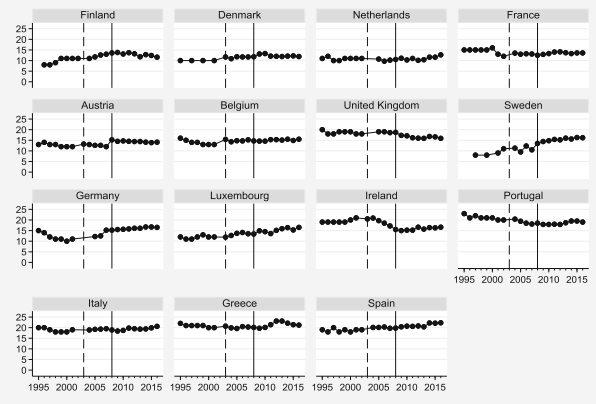

(b) Anchored poverty rates (percentage with income less than $60 \%$ of 2005 national median income)

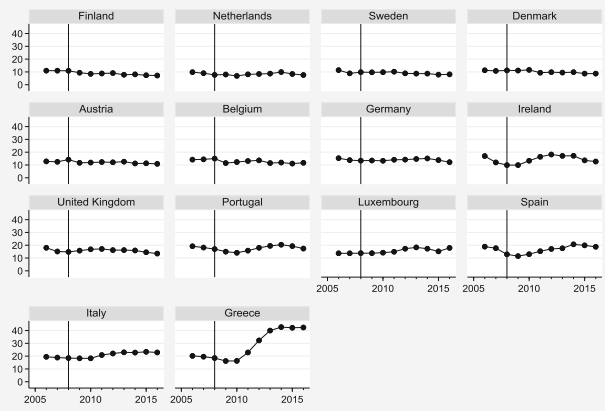

(c) Severe Material Deprivation (SMD) rates (\%)

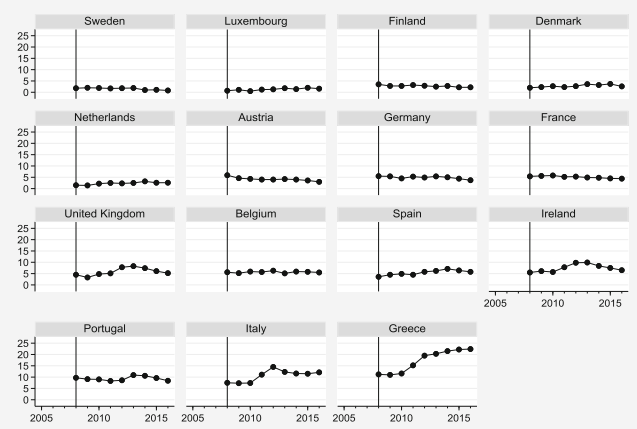

Notes. Countries are sorted by poverty levels in 2016. The definition of SMD is explained in the text. Anchored poverty rates are missing for France. Source: Eurostat Online Database (n.d.)

Fig. 1 Poverty trends, EU15, by measure

tugal. Most strikingly, the AROP rate in Greece rose quickly, by almost 5 percentage points, between 2008 and 2013.

Among the NMS10 (Fig. 1a), the range in AROP rates is as great as among the EU15-from around 10\% in the Czech Republic to nearer 25\% in Bulgaria, Romania, Latvia and Lithuania, depending on the year-but a more general upward trend in 
(a) 'At risk of poverty' (AROP) rates: percentage with income less than $60 \%$ of contemporary national median income)

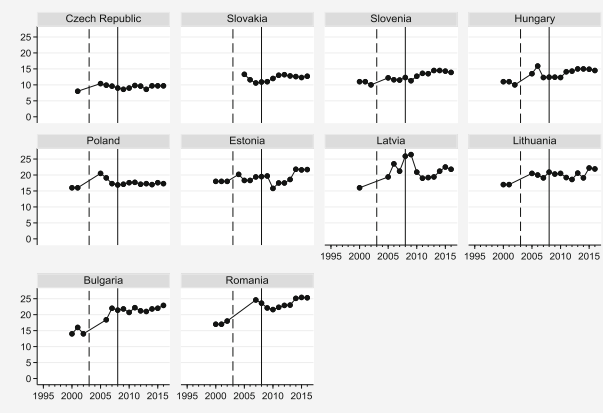

(b) Anchored poverty rates (percentage with income less than $60 \%$ of 2005 national median income)
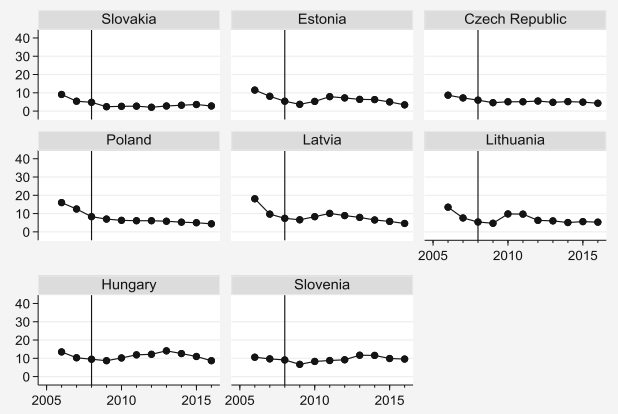

(c) Severe Material Deprivation (SMD) rates (\%)

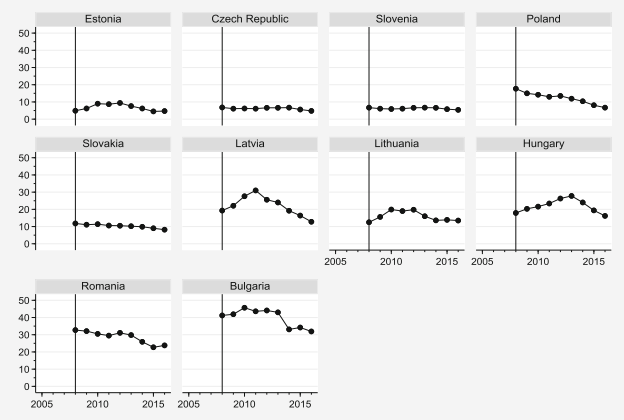

Notes. Countries are sorted by poverty levels in 2016. The definition of SMD is explained in the text. Anchored poverty rates are missing for Bulgaria and Romania. Source: Eurostat Online Database (n.d.)

Fig. 2 Poverty trends, NMS10, by measure

rates is apparent as well as greater year-on-year volatility. It is tempting to attribute these changes to the substantial changes associated with post-Soviet era transition but year-on-year changes of several percentage points also raise questions about data quality. 


\subsection{Why Did 'at Risk of Poverty' (AROP) Rates not Fall Much?}

It is useful to answer this question referring first to the period from the 1990s through to the onset of the Great Recession and then, second, to the period after this. The first period was marked by macro-economic growth, and so the usual expectation would be that poverty rates would also fall. Why was this not the case?

Tony Atkinson gave three main reasons in his 2010 Macerata Lecture. The first is that social inclusion received less priority than economic and employment growth policies over this period. He points to the absence of concrete EU targets for poverty and social inclusion which meant that 'from the outset, social objectives appeared less urgent' (2010: 20). Tony also cites the influence of the High Level Group chaired by Wim Kok which recommended in November 2004 that 'overriding priority be given to economic and employment growth policies' (2010: 10-11) and Tony argues that this recommendation was reflected in the 2005 Mid-Term Review of Lisbon Agenda. In this review, the European Council concluded that it was essential to refocus priorities on growth and employment and Tony refers to a 'down-grading of the social agenda' (2010: 11).

Tony's second reason for lack of progress in poverty reduction is related to one of his enduring themes. Tony points out that:

The Kok Report assumed that increased employment and growth would lead to achievement of the social objectives. This assumption needs to be re-examined. It is reasonable neither to simply assume that the objectives are complementary nor to draw conclusions simply from the fact that poverty has not been reduced. It is after all possible that employment policy worked in the direction of reducing poverty and that, in the absence of the policy, poverty would have increased. (2010: 11).

Characteristically, Tony elaborated on this issue with reference to a model of the labour market, highlighting differences in productivity across workers and emphasising the role of the demand side of the market as well as the supply side. The 'level of employment depends on the willingness of employers to create jobs' (2010: 12) and this willingness depends on the costs associated with hiring and firing, and also recurrent costs including employer social insurance contributions. Raising employment by reducing the reservation wages of workers may not contribute to social inclusion objectives if higher employment is associated with, for example, a rise in the number of low paid workers (he cites the case of Germany). Tony argues that:

Much of the thrust of labour market reform over the pre-crisis period has been in this direction, by reducing the level and coverage of social protection and tightening the conditions under which benefits are paid. (2010: 13).

Tony points out with reference to his labour market model that the adverse effects on the poverty rate need not arise if alternative policies such as reducing the costs of job creation are employed. In this case, the pursuit of the economic and employment policy goal is indeed complementary to achievement of the social objective.

Bea Cantillon (2011) helpfully elaborates on these arguments making detailed reference to the impact of the shift in European policy orientation from 'passive' to 
'activation' strategies, drawing on EU-SILC data for supporting evidence. Her summary view is that:

First, rising employment has benefited workless households only marginally. Consequently the number of job-rich households has increased while the number of jobless households has remained largely unchanged. Second, poverty among unemployed and workless households increased in almost all Member States. Third, new work-related spending-which tends to be less pro-poor-has increased, while the generosity of traditional 'passive' income support declined. ... The conclusion must be that an adapted version of the old redistributive agenda should again be focal in social policymaking, thereby prioritizing adequate minimum income protection and the reinforcement of the redistributive capacity of social programmes. (Cantillon 2011: 445. Emphasis in original.)

Tony Atkinson's third explanation for the lack of marked decline in European poverty rates is what 'appears to have been the over-reliance of the Open Method of Co-ordination on national policy initiatives' (2010: 14). The point is that national policy objectives reflect national priorities and that a lower national emphasis on the achievement of social objectives leads to less progress on poverty reduction. This is where Europe can play a role, Tony believed: 'a significant reduction in European poverty requires concerted European action’ (2010: 14).

In sum, there are clear diagnoses of the reasons why European poverty rates failed to decline in the period prior to the onset of the Great Recession. What about the period after 2009? Explaining a lack of decline is relatively straightforward in terms of countries' economic performance and the nature of the responses to the downturn, including the balance between different types of activation and traditional social protection measures.

Virtually all European countries were hit by the global financial crisis of 2007-2009, though to varying extents, and the accompanying recession brought with it higher unemployment and financial stresses on households. There were variations in the extent to which governments introduced explicit counter-cyclical policies (i.e. over and above 'automatic stabilizer' mechanisms that kicked in). See Jenkins et al. (2013). For example, impacts on households were less in countries such as Germany which implemented short-time working measures which helped those in work (though not already-jobless workers). Rather than experiencing economic recovery subsequently, a number of European countries, especially Southern European ones, were then hit by the sovereign debt crisis of 2011-2013. Particularly during this period, governments placed increasing emphasis on austerity measures aimed at reducing public deficits often with additional cuts in the real value of traditional social protection measures and also in-kind services. On this, with discussion focusing on Southern Europe, see for example Matsaganis and Leventi (2014).

Bea Cantillon's and colleagues' contemporary summary of the situation is that:

There are indeed structural constraints on the increase of the social floor and difficult trade-offs involved in the reconciliation of work and poverty reduction. Differences across countries are, however, enormous. This suggests that there is ample maneuvering space for policymakers. There is also no evidence of a 
universal decrease in the generosity of social protection. Instead, throughout the past decade, many European welfare states were "working harder." However, it appears that increasing financial work incentives was often prioritized, while in many cases additional efforts were not used to raise minimum income packages for jobless households. (Cantillon et al. 2019: 3.)

Put differently, and picking up the themes emphasized by Tony Atkinson and Bea Cantillon regarding the earlier period, the general thrust of social policymaking (as distinct from economic policy-making)_in particular the move towards activation policies rather than traditional passive policies-continued or was intensified in the later period and so there were similar effects (i.e. no decline) on AROP rates.

A potential fourth reason for the lack of decline in AROP rates, and perhaps also the absence of marked rises in them as a result of the Great Recession, is the use of the AROP indicator itself, with trends reflecting the way in which it is defined. Is the EU's headline poverty measure the appropriate one, and how does the picture look if alternatives are used? I turn to these issues in the next section. Perhaps unsurprisingly, we shall see that a shift to poverty indicators with a more absolute character is accompanied by a greater association between trends in the poverty indicator and in national economic performance and also greater cross-national heterogeneity in poverty trends (reflecting the heterogeneity in national economic performance cited above). Tony Atkinson did not cite the definition of poverty indicator (AROP in particular) as an explanation for disappointing poverty trends, though he was clearly very aware of the issues and implications of different definitions - the extensive discussion in his 1998 Poverty in Europe book is but one illustration of this.

\section{Some Conceptual and Measurement Issues}

The EU's headline poverty indicator, the AROP rate, refers to household money income and the low-income cut-off is characterized in terms of contemporary national living standards (a fraction, 60\%, of the median income). It is one particular interpretation of the EU Council's definition of poverty: 'people are said to be living in poverty if their income and resources are so inadequate as to preclude them from having a standard of living considered acceptable in the society in which they live' (Council of the European Union 2004). Poverty today depends on national living standards in the current year; and poverty in one European country is assessed without reference to the living standards of another country.

The potential problems of using such a 'relative' poverty measure are well known (Jenkins et al. 2013). During macro-economic downturns with effects throughout the income distribution not only at the bottom, in particular that reduce median income, it is possible for the headline poverty indicator to decrease. There may be fewer individuals with incomes below the cut-off simply because the cut-off is lower. Similarly, during macro-economic booms that lead to all-round increases in income, including at the median, poverty rates may rise simply because the cut-off has increased. And similar questions may be raised about the appropriateness of using the fully relative measure 
to compare poverty across countries with very different average living standards (see for example Burkhauser 2009).

The question therefore arises of what happens if we use poverty indicators that reflect changes in the real living standards of the poor over time to a greater extent, or their differences across countries. That is, what if we use a more absolute approach to measuring European poverty than the AROP rate, a fully relative indicator? In the rest of this section, I first consider poverty trends for case of anchored poverty rates-rates calculated setting the low-income cut-off as a fraction of a national median in some specific year in the past. (Within each country, the poverty line is fixed in real terms rather than changing over time, as with the AROP indicator.) I also look at how the picture of European poverty changes if one moves to a common EU standard rather than a national one.

Were Europe's headline poverty indicators to be more absolute in nature, this would bring Europe closer to the approach used in the USA - this has a single poverty line for every state of the union, and this line is anchored in real income terms to living standards around the turn of the 1960s. Observe too that the World Bank's estimates of global extreme poverty are also based on an absolute approach. The same poverty line, currently $\$ 1.90$ per day (in purchasing power parity adjusted 'international dollar' terms), is applied to all countries and regardless of the year(s) being considered. (Following recommendations by Atkinson (2017), the Bank is also reporting estimates based on a 'societal poverty line' which combines absolute and relative elements: see World Bank 2018.) At the end of the section, I also look at European poverty patterns using a multiple indicator ('multiple deprivation') approach, one with some 'absolute' features, and consider the extent to which results are correlated with the two incomebased poverty approaches.

\subsection{Poverty Lines Anchored at National Values in $\mathbf{2 0 0 5}$}

Figures $1 \mathrm{~b}$ and $2 \mathrm{~b}$ show trends over time in poverty rates for the EU15 and NMS10 Member States, respectively, where the poverty line is now $60 \%$ of national median income in 2005 (expressed in real income terms). The time series are shorter than in Figs. 2 and 3: estimates are based on EU-SILC data only, and are missing for France, Bulgaria, and Romania. With some exceptions, the general picture of poverty trends is remarkably similar to the trends in the headline relative measure. The trend lines are generally flattish as before, though there is some small decline in anchored poverty rates just before the onset of the Great Recession, reflecting the patterns of economic growth at that time. See for example the cases of Ireland, and many of the NMS.

What is surprising perhaps is that the stalling of economic growth in many EU countries after 2007/8 did not lead to marked increases in anchored poverty rates in most countries. This was because automatic stabilisers kicked in and (in some cases) specific special safety net measures were deployed (Jenkins et al. 2013). See also the earlier discussion.

But it is also important to note the exceptions. In countries most affected by the financial crisis (and later sovereign debt crisis) and growing unemployment, anchored poverty rates did increase much more dramatically_-in Portugal, and especially Spain 


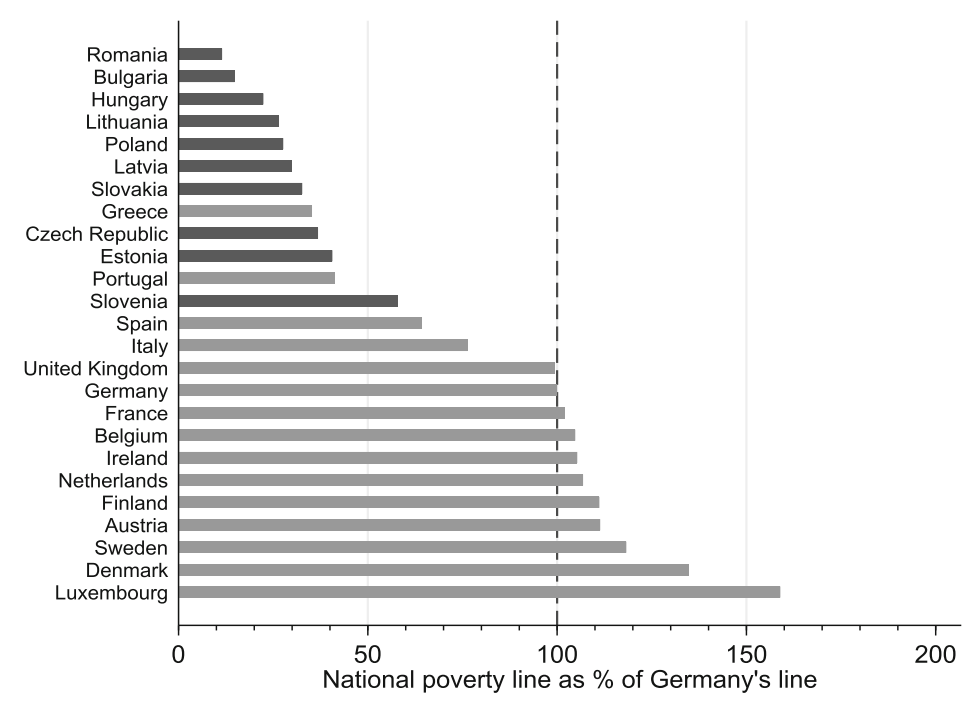

Note. Estimates for EU15 countries are shown in grey and for NMS10 countries in black. The poverty lines refer to those for a single adult household. Source: Eurostat Online Database (n.d.)

Fig. 3 Country-specific ' $60 \%$ of contemporary national median' poverty lines expressed as a percentage of Germany's poverty line, 2016

where the rate more than doubled from just below $10 \%$ in around 2010 to over $20 \%$ in 2014 and Greece where the rate more than doubled from just below $20 \%$ in around 2010 to over $40 \%$ in 2014.

One lesson is that trends in anchored poverty rates reflect national business cycles and average income growth more closely than do trends in the headline AROP indicator. However, if there is little economic growth, trends in the two poverty indicators can be quite similar. Thus use of a relative measure (the AROP rate) rather than an anchored poverty rate is not necessarily the reason why European income poverty rates have not declined markedly.

A separate issue is whether EU poverty monitoring should be based on nationallydefined standards (as now) or should move to some common standard, in particular a line defined with reference to the EU as a whole. In terms of the EU Council's definition (see above), 'the society in which they live' is interpreted as Europe, not the Member State. According to Tony Atkinson, an EU-wide line would represent 'a significant move towards viewing the European Union as a social entity' (Atkinson 1998: 29). Even if individual citizens did not subscribe to that view, the use of an EU-wide line takes into account that individuals' sense of exclusion may be based on a pan-European reference point rather than simply their national context. This makes increasing sense in today's world in which traditional and social media cross borders to reach their audiences.

Because national poverty thresholds differ substantially in real income terms, moving to common EU-wide line makes a substantial difference to patterns of European poverty. Figure 3 reveals the variation in national poverty lines, expressing each 
country's ' $60 \%$ of median' line for a single person in 2016 as a percentage of the corresponding line for Germany. (The chart thus also shows relativities in median income.) In concrete terms, the single-person poverty line for Germany was $€ 12,765$ per year, $€ 20,291$ in Luxembourg (around $170 \%$ of the German line), but only $€ 4500$ in Greece (35\%), and $€ 1469$ in Romania (only $11.5 \%$ of the German line). Put differently, in 2016, a single adult with an income of $€ 10,000$ per year would be counted as poor in Germany using a $60 \%$ of national median poverty line, but non-poor in Italy, Spain, Portugal, Greece, and all of the NMS10 countries. Moving to an EU-wide line, for example $60 \%$ of the EU median in 2016, would imply a line lower than Germany's national line but substantially higher than those in Greece or Romania. And this would of course have consequences for who is counted as poor.

Tony Atkinson (1998) — drawing on his presentation to a European Commission conference a decade earlier-proposed that the reference point issue could be examined by using as a Member State's poverty line a weighted average (a geometric mean) of the national and EU poverty lines, where variations in a parameter $\theta$ allowed a range of possibilities, from the case of fully national lines $(\theta=0)$ to a common EU line $(\theta$ $=1$ ). That is,

Poverty line for country $X=60 \% \times(\text { median income, } X)^{(1-\theta)}$ $\times(\text { median income, } \mathrm{EU})^{\theta}$.

For values of $\theta$ lying strictly between 0 and 1, poverty trends in a country depend not only on economic growth (changes in median income) in that country but also economic growth in the EU as a whole.

Brandolini (2007) was the first to implement Atkinson's idea using data for 21 European countries (for 2000), showing by how much moving towards a common EU line would change the composition of the population counted as poor in Europe. See Fig. 4 which summarizes his estimates. (National and EU-wide lines are each defined as $60 \%$ of their respective medians.) As one moves from left to right (increasing $\theta$ ), the poverty line gives greater weight to the EU median rather than the national median. If fully national lines are used, then 14\% of the individuals poor in the EU25 in 2000 are from Eastern Europe but, if a common EU-line is used, the fraction from Eastern Europe increases to one-half. Over the same range in $\theta$, there is little change in the fraction from Southern Europe, but the fraction from Continental Europe falls by more than one half, from 34 to $13 \%$.

Goedemé et al. (2019) provide updated estimates, for 2008 and 2014, focusing on the case in which the poverty line is $60 \%$ of the year-specific EU median (i.e. the case $\theta=1$ ) and provide more country-specific breakdowns. Figure 5 reproduces their estimates. As in Brandolini's chart, employing a fully EU-wide line means that the countries contributing the most individuals to the EU poverty population are from Eastern Europe-Poland and Romania in particular. Many countries contribute hardly anyone.

The country-specific detail highlights the fact that the country composition of the EU's low-income population depends on both the population of each country and the poverty rate for each country. Shifting to an EU-wide poverty line raises poverty rates 


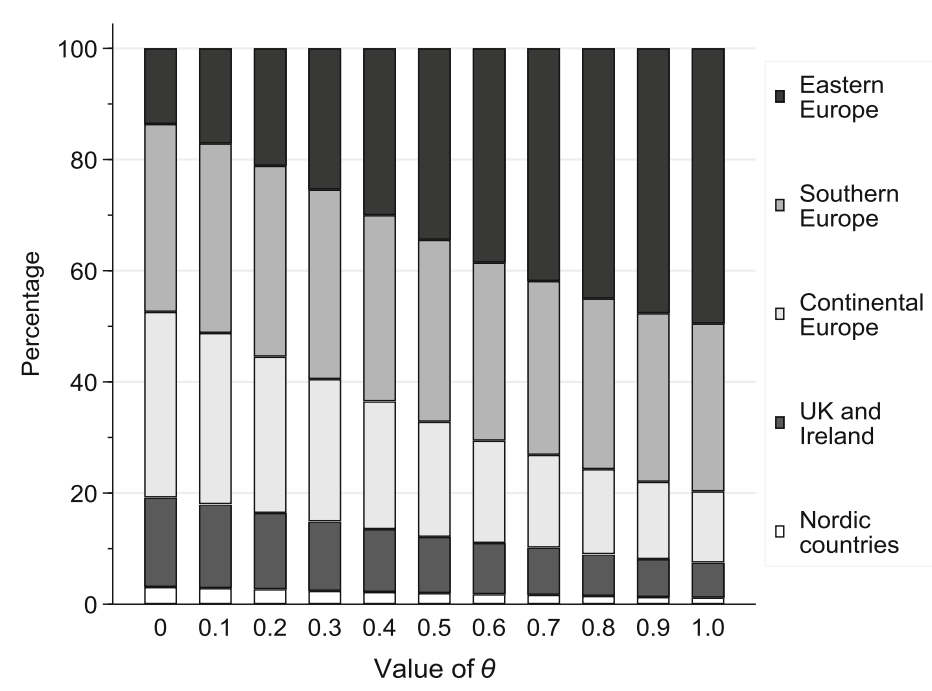

Notes. $\theta=0$ : fully national lines. $\theta=1$ : common EU line. National and EU-wide lines are each defined as $60 \%$ of their respective medians. 'Europe' is 21 Member States here. Eastern Europe: CZ, EE, HU, PL, SI, SK. Southern Europe: EL, IT, PT, ES. Continental Europe: AT, BE, DE, FR, LU, NL. Nordic countries: DK, FI, SE. Calculations are based on ECHP data for all countries except Eastern Europe for which LIS data were used. Source. Brandolini (2007: Figure 3.3), redrawn by the author.

Fig. 4 The regional composition of Europe's low-income population, by value of $\theta, 2000$

in relatively poor countries (mostly New Member States) but this has little effect on the composition of the EU low-income population unless the country is relatively large (compare Poland and Romania with Slovenia, Estonia, Latvia and Lithuania, for example). At the same time, the shift to an EU-wide poverty line reduces poverty rates in relatively rich countries, but a country continues to contribute relatively large numbers of individuals to the EU total if it has a large population. Look at the cases of Germany, UK, Spain, and Italy for instance.

Goedemé et al.'s (2019) estimates of the country-specific poverty rates in 2008 and 2014 based on the EU-wide poverty line are shown in Fig. 6. The proportion of individuals in the EU27 with an income less than $60 \%$ of the EU median is around $20 \%$ in both years. Virtually all the countries with poverty rates less than the EU27 rate are the relatively rich countries of the original EU15; those with rates greater than the EU27 rate are the relatively poor New Member States. Poverty rates using the EUwide standard fell sharply for Slovakia, Poland and Estonia but rose substantially for Greece. The estimates shown in the figures also remind us that, although France is the second most populous country in the EU, it contributes relatively few people to the EU low-income population because its poverty rate according to the EU-wide measure is relatively low. The Czech Republic, the third most populous country among the NMS, also contributes few people to the EU low-income population for the same reason. By contrast, Poland and Romania have large populations - they are two most populous NMS (and ranked 6th and 7th in the EU as a whole) - and relatively high poverty rates. 


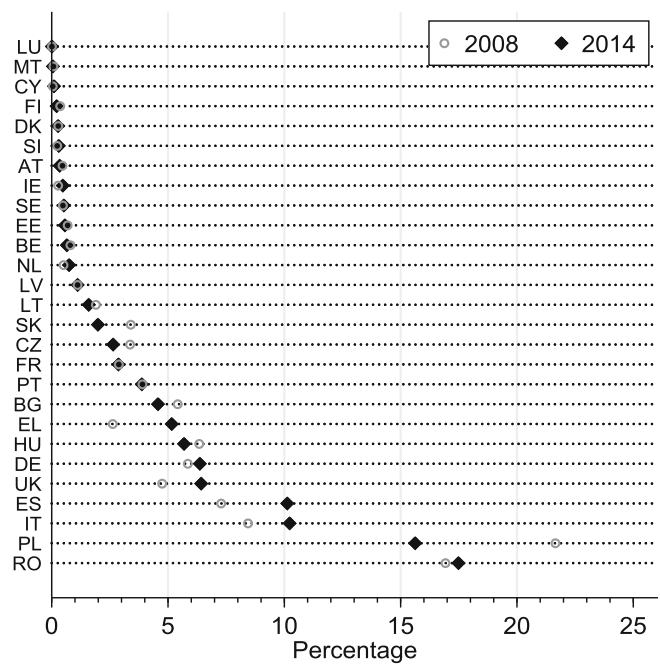

Note. The EU-wide poverty lines for 2008 and 2014 are 60 per cent of the year-specific EU-wide median income. The grey circles show 2008 estimates and the black diamonds show 2014 estimates. Countries ranked by EU-SILC 2014 values. Source: Goedemé et al. (2019: Figure 4), redrawn by the author.

Fig. 5 The Member State composition of the EU-27's low-income population (EU-wide threshold), EUSILC 2008-2014

Use of a common EU-level poverty standard raises uncomfortable challenges for policy. Clearly, the more we move towards a common pan-EU poverty threshold, the greater the prevalence of poverty that is recorded for the New Member States. This brings back to the issue of the role of EU-level versus national-level policy initiatives and the nature of the EU's Open Method of Coordination. If the estimates arising from embracing of a common EU-level poverty standard are to be taken seriously and to guide policy, then the current reliance on national initiatives needs modification. EUlevel strategies and coordination are required but development of these requires all of the Member States to sign up to them. If part of the solution to poverty problem is more transfers from richer EU Member States to poorer ones, then getting that collective agreement may be difficult. I return to this tension later on.

\subsection{Poverty as Material Deprivation}

First, however, I consider the role of a different measurement approach-the material deprivation one-to consider how it changes the picture of EU poverty from the income-based approach. The idea behind the material deprivation approach is, of course, that poverty is not all (or not at all) about a lack of money-and that one should look directly at people's circumstances. The EU's implementation follows closely the measurement tradition pioneered by Peter Townsend (1979) in the UK. The approach also introduces some 'absolute' components into the poverty measure, complementing the 'relative' features of the AROP rate, in particular (more on this below). 


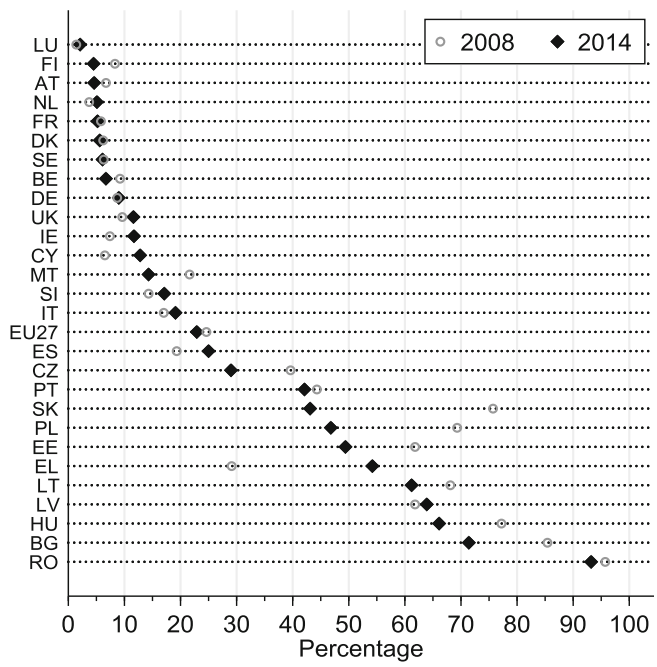

Note. The EU-wide poverty lines for 2008 and 2014 are 60 per cent of the year-specific EU-wide median income. The grey circles show 2008 estimates and the black diamonds show 2014 estimates. Countries ranked by EU-SILC 2014 values. Source: Goedemé et al. (2019: Figure 2), redrawn by the author.

Fig. 6 Percentage poor, by Member State (EU-wide poverty line), EU-SILC 2008-2014

Table 2 Poverty as material deprivation: 9 binary indicators of inability to afford
Cannot afford

1. Pay rent or utility bills

2. Keep home adequately warm

3. Face unexpected expenses

4. Eat meat, fish, or protein equivalent every second day

5. Have a week's holiday away from home

6. Car

7. Washing machine

8. Colour TV

9. Telephone

The EU currently summarizes material deprivation using 9 indicators. (The basket of indicators is currently being modified: see Guio and Marlier 2017 for the background.) The indicators are listed in Table 2 and cover the inability to afford items related to food, clothing and shelter (items 1-4), social participation (item 5), and possession of durables (items 6-9). There are of course important issues about how to summarise data on a dashboard of 9 binary indicators (to which I return below). For the purposes of this paper, I focus on the EU's measure of 'severe material deprivation' (SMD), which identifies individuals unable to afford four or more items out of the nine.

Figures 1c and 2c show country-specific estimates of trends in SMD rates for the EU15 and NMS10. Among the EU15 the majority of the countries have relatively low 
SMD rates (around 5\%) and rates that have changed little over the decade up to 2016 (apart from a rise in the UK and Ireland to 2012 followed by decline). Portugal, Italy, and Greece stand out because their SMD rates are around 10\% at the start of the period, and increase markedly thereafter, especially in Greece (a rate of over 20\% in 2016). The NMS10 stand out too, because SMD rates are higher than in EU15 countries for many of them. The rates are around 5\% at the onset of the Great Recession for only three countries (EE, CZ, SI), but reach around 45\% in Bulgaria in 2010. The rate for Bulgaria is around one-third in 2014-2016. Compared to the EU15, there is a more distinct decline in SMD rates as the decade progressed.

More generally, it appears that trends over time in countries' SMD rates tend to be more similar to trends in their anchored poverty rates (Figs. $1 b$ and $2 b$ ) than to the trends in their AROP rates (Figs. 1a and 2a). Both SMD and anchored poverty measures are reliant on components that are not updated over time-the deprivation items and cut-off, and real income poverty line. The ranking of countries according to SMD rate is not necessarily the same as the ranking by income poverty rate.

Figure 7 shows for 2016 the relationship at the country level between rates of SMD and income poverty according to the headline AROP indicator, a relative measure. The dashed lines show the EU27 averages for each measure. If there were a perfect correlation between the two measures, i.e. if they provided the same information about the situation of each Member State relative to others, each country data point would lie on or close to a straight line fitted through the data points. Clearly this is not the case. Although a fitted regression line would have a positive slope, there would be substantial variation around the line with dispersion greater at above-average AROP rates. This description applies regardless of whether the line is fit to the EU15 only, NMS10 only, or all 25 countries. It appears that although there is much variation across the EU15 countries in AROP rates, there is relatively little variation in SMD rates aside from outliers such as Portugal, Italy and especially Greece with relatively high SMD rates.

Instead there appears to be a closer relationship between the SMD rate and the poverty rates based on the common EU-wide standard shown in Fig. 6. The set of countries with the ten highest SMD rates in 2016 is almost identical to the set in 2014 with the ten highest poverty rates based on the common $60 \%$-of-EU-median line. The only difference is that Italy appears in the former list but not the latter, and vice versa for Estonia.

In sum, the material deprivation approach paints a different picture of poverty across Member States than the headline, most commonly-used indicator, the AROP measure. (See also Fahey 2007 on this.) There are particular features of the material deprivation measure contributing to this. In particular the SMD measure is based on a common EU list of items which is applied to each Member State, and over the period under consideration the list of items has not been updated-there are absolutist features built into the indicator. By contrast, the headline relative measure (AROP) is based on national medians and updated in line with the change in 'average' (median) national living standards.

The apparently closer relationship between SMD rates and income poverty rates based on an EU-wide standard does not imply that one approach has greater validity than another. Assessments of validity are contingent on agreement about the fundamental concepts being measured. Experience suggests that it is hard to secure consensus 


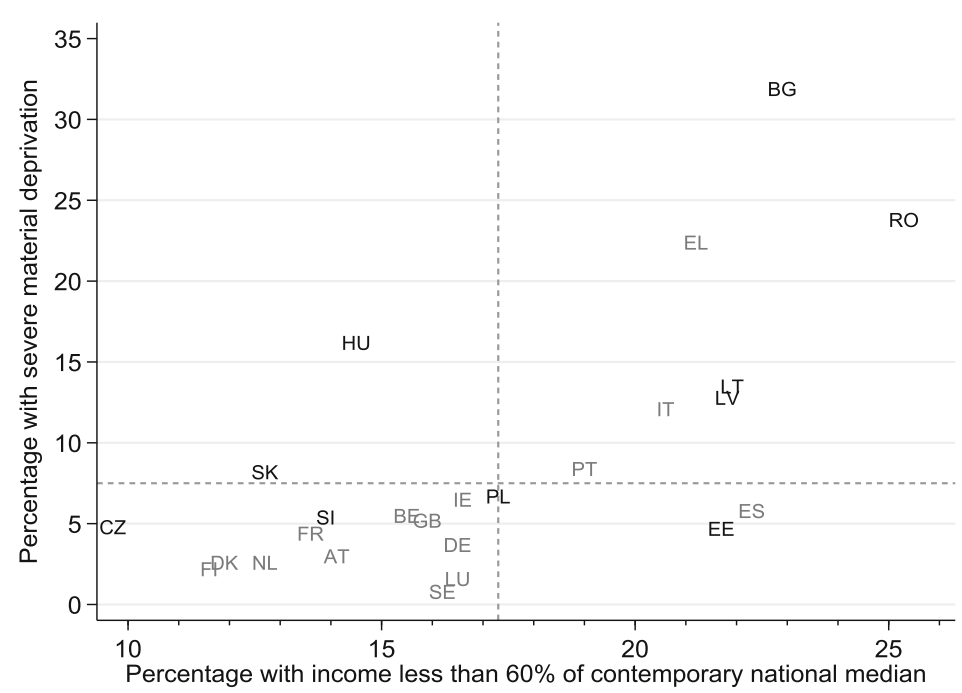

Note. Estimates for EU15 countries are shown in grey and for NMS countries in black. Dashed lines show EU27 averages. Source: Eurostat Online Database (n.d.)

Fig. 7 Association between rates of SMD and AROP, 2016

about whether to prioritize relative or absolute income measures, and there are enduring debates about the roles of income and material deprivation in summarizing poverty. And there are of course many conceptual issues with the multiple deprivation approach that I have not considered. These include questions such as the choice of indicators and hence dimensions of deprivation, the use of binary versus categorical or continuous measures, the choice of deprivation cut-offs in each dimension, and how to count deprivations and whether and how to weight them. Many of these issues are considered in the recent literature on multidimensional poverty. For pioneering papers, see e.g. Atkinson (2003), Bourguignon and Chakravarty (2003) and Alkire and Foster (2011). Alkire et al. (2014) is one of the first papers to apply the Alkire-Foster approach to EU-SILC data.

The way forward is not to treat the choice of poverty indicator as if it were a binary choice between black and white. Instead one should treat the multiple sources of information as complements rather than substitutes, recognising that they each incorporate different features (which individuals may attribute different levels of importance to), and one should use all of them as a means to better to describe and understand changes in household circumstances. As put by Tony Atkinson and co-authors, ' $[w]$ ithout complementing the analysis of cross-sectional and longitudinal income-based indicators with that of cross-sectional and longitudinal MD [material deprivation] variables, part of the explanation behind these trends would have been missed' (Atkinson et al. 2017: 42-43). Relatedly, a major theme of Tony's final book (2019) is that ' $[t]$ there is not a single monolithic concept. The meaning and interpretation of poverty is contested and we need to consider different approaches to its measurement. ... In order to understand what lies behind these differing indicators, we have to ask the fundamental 
question as to the source of our concern about poverty and to recognise that people may legitimately hold different views (2019: 211-212).

If one does emphasize the material deprivation approach, then the policy targeting issues that I cited earlier in the context of the EU-wide measures arise again. The countries with the highest SMD rates are mainly New Member States and Greece, and there is the political issue of whether-or how - this finding might be translated in a greater targeting of EU-level actions to alleviate the problems identified in these countries.

There are also other indicators of the changes in living standards that could be employed alongside those mentioned so far. For instance, the Eurostat Online Database (n.d.) provides EU-SILC-based estimates of quantile group shares of total income by year and country. The World Bank and OECD are now placing emphasis on concepts such as 'shared prosperity' and 'inclusive growth' respectively. Shared prosperity is commonly summarised in terms of (changes in) the share of total income held by the poorest $40 \%$. (For a discussion of interpretations and links with other measures, see Ferreira et al. 2018.) Tony Atkinson supported the use of this indicator, but also recommended that the real income levels of the poorest $40 \%$ should be examined. See Atkinson et al. 2017, especially section 1.4.4) in the European context and Atkinson (2017) in a global context. Also not considered here are the relative merits of measuring of living standards in terms of consumption expenditure rather than income. See Atkinson $(1998,2017,2019)$ for reviews of the issues, and Serafino and Tonkin (2017) for an EU-SILC application employing income, expenditure, and material deprivation measures.

\subsection{Multiple Measures and the EU2020 Social Inclusion Target}

The issues of whether different measures provide similar information about Member States and the circumstances of households within them has arisen again in the context of the EU2020 Social Inclusion target. This is because the target refers not only to income poverty and material deprivation but also to being in a very low-work intensity household. More precisely, the 'Fighting poverty and social exclusion' target refers to 'a least 20 million fewer people in or at risk of poverty and social exclusion'. Monitoring progress is based on comparisons of counts of persons who are: (1) at risk of income poverty (measured using $60 \%$ of contemporary national median line), or (2) severely materially deprived, or (3) living in households with very low work intensity. On the one hand, individuals are only counted once in the total even if they are present in more than one of the three sub-indicator counts. However, on the other hand, a reduction in headline EU2020 count is possible via a reduction in any one of the three dimensions.

The EU2020 approach is a 'counting' approach to the aggregation of the subindicators in which the overall headline indicator requires an individual to be 'deprived' on all of the dimensions summarized by the sub-indicators. Figure 8 shows that using different indicators leads to different results. It displays for EU Member States in 2016 a plot of country percentages of persons with at least one EU2020 problem against the country percentages of persons with all three problems. (In the terminology of 


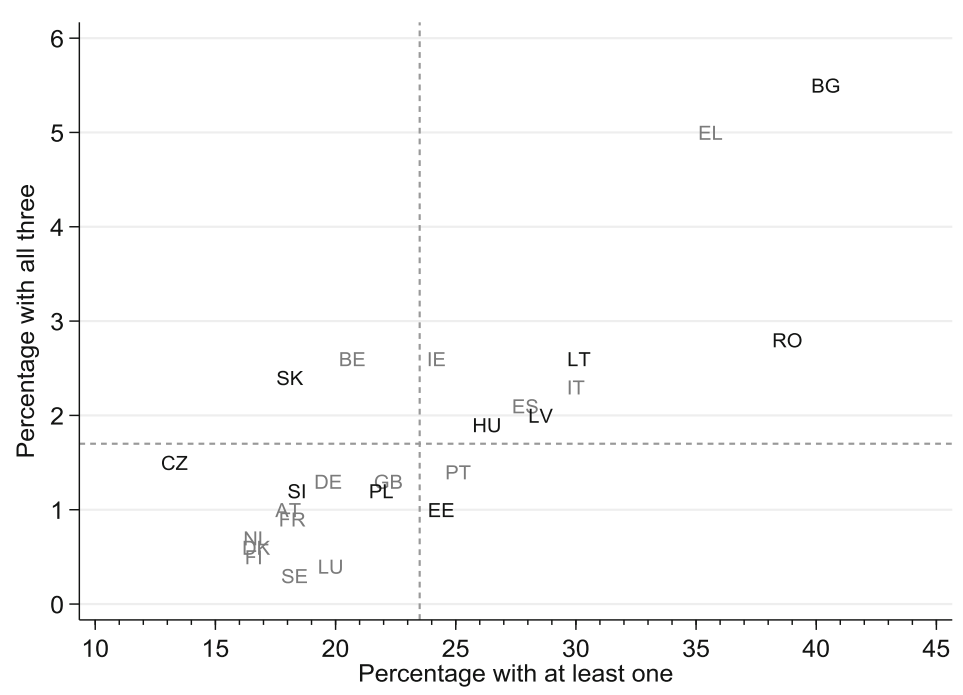

Note. Estimates for EU15 countries are shown in grey and for NMS countries in black. Dashed lines show EU27 averages. Source: Eurostat Online Database.

Fig. 8 Association between percentage with at least one EU2020 problem and percentage with all three EU2020 problems, 2016

multidimensional poverty measurement, the former corresponds to a 'union' approach, the latter to an 'intersection' approach: see Aaberge and Brandolini 2015.) Although the correlation between percentages is positive, the relationship is weak. It is stronger among the EU15 than the NMS10 but, even so, there are clear outliers such as Belgium and Ireland with relatively high percentages of persons with all three problems. Among the NMS there is substantial heterogeneity. Romania, Greece, and Bulgaria each have similar percentages of individuals with at least problem (between 35 and 40\%), but Greece and Bulgaria have markedly higher percentages of individuals with all three problems (between 5 and $6 \%$ compared with less than $3 \%$ ).

There are further issues concerning the target which deserve attention. Is the use of three indicators official recognition that each indicator picks up different information (the issue raised in the previous paragraphs)? Or, more cynically, is the target's specification simply a politically expedient way of avoiding making a decision about what 'poverty' really is?

\section{The Future Direction of EU-Level Anti-Poverty Actions}

The discussion so far has argued that, substantial progress has been made over the last two to three decades in EU-level initiatives in statistical monitoring of poverty and social exclusion and in developing an anti-poverty agenda. But at the same time the prevalence of poverty remains stubbornly high (and according to a range of measurement approaches). The progress cited has always involved a mixture of reliance 


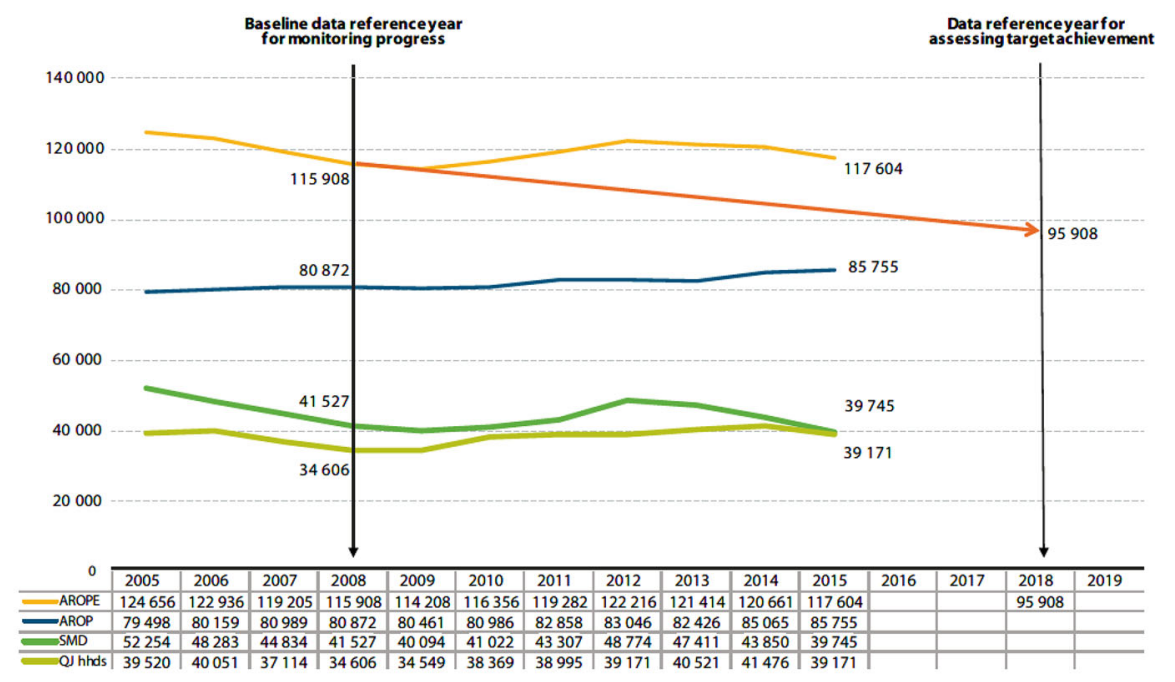

Note. The chart shows the evolution of the number (in thousands) of persons living in quasi-jobless households (QJ), in severe multiple deprivation (SMD), and at risk of income poverty (AROP). AROPE is the combined indicator used to assess progress towards the EU2020 target. See main text for details. Source: Atkinson et al. (2017: Figure 1.1).

Fig. 9 Progress towards the EU social inclusion target, 2005-2015

on EU-level and national-level initiatives relating to, for example, the way in which the monitoring indicators are defined. And at the heart of the EU's current approach is the combination of the EU-level Open Method of Coordination regarding higher level strategizing, but implementation is centred around national action plans and their policies. In this final section, I reflect on how monitoring might develop (nature of indicators, data), whether the shape of the anti-poverty strategy should change, and whether we should be pessimistic or optimistic about progress. Once again I draw heavily on the work of Tony Atkinson.

Figure 9, summarizing progress towards meeting the EU2020 target, and taken from Atkinson et al. (2017), is the starting point. Year 2008 provides the baseline data for assessing progress towards the '20 million fewer' target for 2020. Reading upwards from the bottom, the lines show the evolution of the numbers of individuals in quasi-jobless household rate (QJ), in severe material deprivation (SMD) and at risk of poverty (AROP, as described earlier). The number at risk of poverty or social exclusion (AROPE) is the combination of the information about AJ, SMD and AROP using the rules for calculating the EU2020 indicator cited in the previous section. The EU2020 target would be achieved if the number of persons AROPE in 2008, 115.908 million, fell to 95.908 million or fewer by 2020 : look at the line with the arrowhead.

The headline result is the lack of progress towards meeting the EU2020 target so far. As of 2016, the number of persons AROPE was larger (117.604 million) rather than smaller than the baseline number for 2008. The chart also shows that the only sub-indicator of the three that is heading in the right direction is the SMD one. 


\subsection{Grounds for Pessimism?}

A pessimistic reaction about the possibility of progress towards the EU2020 target seems justified on the basis of this evidence, especially when one takes into account the changes in the socio-economic context that may hinder EU-level initiatives and many national ones. I am referring not only to the nature of macroeconomic environment (discussed earlier) though clearly it is relevant that many policy-makers argue that addressing social problems should take lower priority to economic ones in this Austerity Era. It is also that the 'EU' itself has changed and continues to evolve substantially as a result of enlargement and migration, both internally and from outside the EU. There are distinct differences in economic performance across Member States. With the nationalistic surge in many Member States, including the Brexit referendum vote in the UK, it would seem to be hard to argue that there is sufficient cross-national solidarity for more concerted supra-national EU-level initiatives in social policy.

Put differently, the prospect of introducing new anti-poverty policies such as an EUwide basic income for children as proposed by Tony Atkinson in his 2010 Macerata Lecture seems infeasible in the current climate and so not worth arguing for.

\subsection{Or Grounds for Optimism?}

Tony Atkinson's reaction was at odds with the pessimistic view, and he continued to make suggestions about what he thought would be fruitful progress on anti-poverty policy measures. In the European context, he made several proposals together with co-authors Guio and Marlier (2017). They recommend continuing to improve the current monitoring infrastructure and the Open Method of Coordination, making a principled case for effective policies and policy analysis. They write about increasing (not decreasing) the EU's ambition-to look beyond 2020 for framing EU targets and to draw on the Sustainable Development Goals framework (which refer to 2030 targets). The SDGs are now global in scope (about rich countries as well as poor ones, unlike the Millennium Development Goals) and incorporate national poverty objectives in their targets. This leads Tony and colleagues to suggest, inter alia, that the EU should also add indicators of 'extreme poverty' and of 'real income growth of poorest 40\%' to existing EU social indicators. They stress that the five EU2020 targets and policies directed at them should not be looked at in isolation; economic and social goals and measures need to be looked at together.

Tony and colleagues also give reasons for their proposed strategy:

Faced with such failure [to make good progress towards the EU2020 targets], Europe's leaders may simply decide to throw in the towel, and write off 2010-2020 as a 'lost decade'. The Europe 2020 objective of a reduction of a sixth may simply be pushed 10 years into the future. Such an outcome would be extremely disappointing to those concerned with the social dimension of Europe, and devastating for the millions of Europe's citizens living at risk of poverty or social exclusion. We believe that the SDGs, with their greater ambition, should be the basis for setting Europe's commitment for 2030. Halving poverty by 2030 
should not be beyond the resources of a rich continent. (Atkinson et al. 2017: 46-47).

Tony's reactions to the progress relative to the EU2020 benchmarks are further evidence of his enduring themes and traits that I referred to in the Introduction. There is persistence in his views about the direction of social security policy as well. Tony strongly believed in the social insurance model, highlighting problems that arise with a reliance on means-testing, but he was also very much open to supplementation through forms of basic income schemes. His 2010 Macerata Lecture proposal for an EU-wide basic income for children was predated by consideration of a 'participation income' (a basic income conditional on making an appropriate social contribution, which could including caring as well as paid work) in his 1998 Poverty in Europe book. He returned to the same idea in Inequality. What Can be Done? (2015) addressing financing in great detail in order to demonstrate that his proposals were feasible.

When I was first thinking about future directions in EU poverty monitoring and policy, I was a pessimist of the kind I characterized earlier. But I have changed my mind after re-reading Tony Atkinson's work-something that has happened a lot during my career! I now think that to be pessimistic is to be defeatist; to make progress happen, you have to believe, optimistically, that progress is possible-just as Tony did. As ever, he puts the case eloquently and persuasively. In the final section of his 2015 book, Tony emphasised that social progress had been made over the longer term. He acknowledged contemporary problems, but argued that further progress was possible and something we should explicitly aim for:

I have written this book in a positive spirit. I have stressed the importance of looking back in time, but I do not believe that we have returned to a world like that when Queen Victoria was alive. ... It is true that since 1980 we have seen an "Inequality Turn" and that the twenty-first century brings challenges in terms of ageing of the population and climate change. But the solutions to these problems lie within our own hands. If we are willing to use today's greater wealth to address these challenges, there are indeed grounds for optimism. (Atkinson 2015: 308).

Tony will continue to inspire us and influence our work on European poverty and anti-poverty policy - and all the other topics he worked on. This paper has shown that further work is required on the advantages and disadvantages of different poverty indicators, taking into account not only conceptual issues but also those of empirical implementation related to data availability and quality, as well as on issues of the political economy of anti-poverty policy in an era that continues to be dogged in many countries by austerity and greater questioning of the roles of EU-level versus national institutions and initiatives.

Acknowledgements This paper is based on keynote addresses to the European Commission Workshop on Income Inequality and its Policy Determinants, Brussels (September 2018), the LIS User Conference, Luxembourg (May 2018), and the International Conference on Inequality, Bologna (November 2017). Some of the material was also presented at the ' 50 Jahre IAB' Jubiläum, Berlin (April 2017). For comments I am grateful to Andrea Brandolini and two referees. Thanks to Tim Goedemé for supplying the data underlying charts from Goedemé et al. (2019). The research was part supported by an Australian Research Council Discovery Grant (award DP150102409, with Richard Burkhauser, Nicolas Hérault, and Roger Wilkins) and core funding of the Research Centre on Micro-Social Change at the Institute for Social and 
Economic Research by the University of Essex and the UK Economic and Social Research Council (award ES/L009153/1).

Open Access This article is distributed under the terms of the Creative Commons Attribution 4.0 International License (http://creativecommons.org/licenses/by/4.0/), which permits unrestricted use, distribution, and reproduction in any medium, provided you give appropriate credit to the original author(s) and the source, provide a link to the Creative Commons license, and indicate if changes were made.

\section{References}

Aaberge R, Brandolini A (2015) Multidimensional poverty and inequality. In: Atkinson AB, Bourguignon F (eds) Handbook of income distribution, vol 2A. Elsevier, Amsterdam, pp 141-216

Aaberge R, Bourguignon F, Brandolini A, Ferreira FG, Gornick JC, Hills J, Jäntti M, Jenkins SP, Marlier E, Micklewright J, Nolan B, Piketty T, Radermacher WJ, Smeeding TM, Stern NH, Stiglitz JE, Sutherland H (2017) Tony Atkinson and his legacy. Rev Income Wealth 63(3):412-444

Alkire S, Foster JE (2011) Counting and multidimensional poverty measurement. J Public Econ 95:476-487 Alkire S, Apablaza M, Jung E (2014) 'Multidimensional poverty measurement for EU-SILC countries', Research in Progress Working Paper 36c. Oxford University, OPHI, Oxford

Atkinson AB (1998) Poverty in Europe. Blackwell Publishers, Oxford

Atkinson AB (2003) Multidimensional deprivation: contrasting social welfare and counting approaches'. J Econ Inequal 1(1):51-65

Atkinson AB (2009) An enlarged role for tax-benefit models. In: Lelkes O, Sutherland H (eds) Tax and benefit policies in the enlarged Europe: assessing the impact with microsimulation models. Ashgate, Farnham, pp 33-46

Atkinson AB (2010) 'Poverty and the EU: the new decade' (Macerata Lecture on European Economic Policy), Working Paper 24. Università degli Studi di Macerata, Dipartimento di Studi sullo Sviluppo Economico, Macerata

Atkinson AB (2015) Inequality. What can be done. Harvard University Press, Cambridge

Atkinson AB (2017) Monitoring global poverty. Report of the commission on global poverty. The World Bank, Washington DC

Atkinson AB (2019) Measuring poverty around the world. Princeton University Press, Princeton and Woodstock

Atkinson AB, Marlier E (eds) (2010) Income and living conditions in Europe. Eurostat, Luxembourg

Atkinson AB, Micklewright J (1992) Economic transformation in eastern europe and the distribution of income. Cambridge University Press, Cambridge

Atkinson AB, Rainwater L, Smeeding T (1995) Income distribution in OECD countries. Evidence from the Luxembourg Income Study. OECD, Paris

Atkinson AB, Cantillon B, Marlier E, Nolan B (2002) Social indicators. The EU and social inclusion. Oxford University Press, Oxford

Atkinson AB, Guio A-C, Marlier E (eds) (2017) Monitoring social inclusion in Europe. 2017 edn. Eurostat, Luxembourg, pp 33-49

Bourguignon F, Chakravarty S (2003) The measurement of multidimensional poverty. J Econ Inequal 1(1):25-49

Brandolini A (2007) Measurement of income distribution in supranational entities: the case of the European Union. In: Jenkins SP, Micklewright J (eds) Inequality and poverty re-examined. Oxford University Press, Oxford, pp 62-83

Burkhauser RV (2009) Deconstructing European poverty measures: what relative and absolute scales measure. J Policy Anal Manag 28(4):715-724

Cantillon B (2011) The paradox of the social investment state: growth, employment and poverty in the Lisbon era. J Eur Soc Policy 21(5):432-449

Cantillon B, Goedemé T, Hills J (2019) Introduction. In: Cantillon B, Goedemé T, Hills J (eds) Decent incomes for all: improving policies in Europe. Oxford University Press, Oxford, pp 1-9

Council of the European Union (2004) Joint report by the Commission and the Council on Social Inclusion. Council of the European Union, Brussels

Eurostat (n.d.) Online Database. http://ec.europa.eu/eurostat/data/database 
Fahey T (2007) The case for an EU-wide measure of poverty. Eur Sociol Rev 23(1):35-47

Ferreira F, Galasso E, Negre N (2018) 'Shared prosperity: concepts, data, and some policy examples', Discussion paper 11571. IZA, Bonn

Goedemé T, Zardo Trindade L, Vandenbroucke F (2019) A pan-European perspective on low-income dynamics in the EU. In: Cantillon B, Goedemé T, Hills J (eds) Decent incomes for all. Improving policies in Europe. Oxford University Press, Oxford, pp 56-82

Guio A-C, Marlier E (2017) Amending the EU material deprivation indicator: impact on size and composition of deprived population. In: Atkinson AB, Guio A-C, Marlier E (eds) Monitoring social inclusion in Europe, 2017th edn. Eurostat, Luxembourg, pp 193-207

Hagenaars AJM, de Vos K, Zaidi MA (1994) Poverty statistics in the late 1980s: research based on microdata. Office for Official Publications of the European Community, Luxembourg

Hagenaars AJM, de Vos K, Zaidi MA (1998) Patterns of poverty in Europe. In: Jenkins SP, Kapteyn A, Van Praag BMS (eds) The distribution of welfare and household production-international perspectives. Cambridge University Press, Cambridge, pp 25-49

Jenkins SP (1999) Measurement of the income distribution: an academic user's view'. In: European Advisory Committee on Statistical Information in the Economic and Social Spheres (CEIES), Proceedings of the 7th CEIES Seminar on Income Distribution and Different Sources of Income. Eurostat, Luxembourg

Jenkins SP (2017) Anthony B. Atkinson (1944-). In: Cord R (ed) The Palgrave companion to Cambridge economics. Palgrave Macmillan, Basingstoke, pp 1051-1074

Jenkins SP, Brandolini A, Micklewright J, Nolan B (eds) (2013) The great recession and the distribution of household income. Oxford University Press, Oxford

Marlier E, Atkinson AB, Cantillon B, Nolan B (2007) The EU and social inclusion. facing the challenges. The Policy Press, Bristol

Matsaganis M, Leventi C (2014) 'The distributional impact of austerity and the recession in Southern Europe. South Eur Soc Politics 19(3):393-412

O’Higgins M, Jenkins SP (1990) Poverty in the EC: 1975, 1980, 1985. In: Teekens R, van Praag B (eds) Analysing poverty in the European Community, Eurostat News Special Edition 1-1990. Eurostat, Luxembourg, pp 190-211

Sawyer M (1976) 'Income distribution in OECD countries', OECD Economic Outlook. OECD, Paris

Serafino P, Tonkin R (2017) Comparing poverty estimates using income, expenditure and material deprivation. In: Atkinson AB, Guio A-C, Marlier E (eds) Monitoring social inclusion in Europe, 2017th edn. Eurostat, Luxembourg, pp 241-258

Townsend P (1979) Poverty in the United Kingdom: a survey of household resources and standards of living. Penguin, Harmondsworth

Vandenbroucke F (2002) Foreword. In: Atkinson AB, Cantillon B, Marlier E, Nolan B (eds) Social indicators. The EU and social inclusion. Oxford University Press, Oxford, pp v-xi

World Bank (2018) Poverty and shared prosperity 2018: piecing together the poverty puzzle. World Bank, Washington DC

Publisher's Note Springer Nature remains neutral with regard to jurisdictional claims in published maps and institutional affiliations. 